\title{
Macrophages in diabetes mellitus (DM) and COVID-19: do they trigger DM?
}

\author{
Małgorzata Kloc ${ }^{1,2,3} \cdot$ Rafik M. Ghobrial ${ }^{1,2} \cdot$ Sławomir Lewicki ${ }^{4}$ - Jacek Z. Kubiak ${ }^{4,5}$ \\ Received: 28 August 2020 / Revised: 28 August 2020 / Accepted: 12 October 2020 / Published online: 17 October 2020 \\ (C) Springer Nature Switzerland AG 2020
}

\begin{abstract}
Diabetes mellitus (DM) augments the risk of hospitalization and mortality resulting from viral, bacterial, or fungal pathogen infection. This has been also true for the past SARS and MERS, and current SARS-CoV-2 coronavirus epidemics. Clinical data indicate that SARS-CoV-2 infection triggers a severe course of COVID-19 more frequently in diabetic than non-diabetic patients. Here we overview the cellular and molecular mechanisms associated with this phenomenon. We focus on alterations in the immune cells, especially monocytes and macrophages, involved in innate immune response and inflammatory processes, which differ in type 1 diabetes mellitus (T1DM) and type 2 diabetes mellitus (T2DM). We also describe the DM-related changes in the monocyte/macrophages functions, how they could lead to the severe outcome of SARS-CoV-2 infection, and importantly, if and how they could initiate DM in DM-susceptible patients.
\end{abstract}

Keywords Diabetes mellitus $\cdot$ Macrophages $\cdot$ SARS-CoV-2 $\cdot$ COVID-19

\section{Pancreatic macrophages}

Diabetes occurs when the excess of glucose accumulates in the blood because the pancreas, an organ responsible for the homeostasis of glucose in the bloodstream, is not producing enough insulin. The pancreas is a heterocrine gland that has food digestive (exocrine) and hormonal (endocrine) function. In its exocrine capacity, the pancreas produces hormones insulin, which lowers glucose level, and glucagon, which raises

Małgorzata Kloc

mkloc@houstonmethodist.org

Jacek Z. Kubiak

jacek.kubiak@univ-rennes1.fr

1 The Houston Methodist Research Institute, 6670 Bertner Ave, Houston, TX 77030, USA

2 Department of Surgery, The Houston Methodist Hospital, Houston, TX, USA

3 Department of Genetics, The University of Texas, M.D. Anderson Cancer Center, Houston, TX, USA

4 Department of Regenerative Medicine and Cell Biology, Military Institute of Hygiene and Epidemiology (WIHE), Warsaw, Poland

5 UnivRennes, UMR 6290, CNRS, Institute of Genetics and Development of Rennes, Cell Cycle Group, Faculty of Medicine, 2 Ave. du Prof. Leon Bernard, 35043 Rennes Cedex, France glucose level, and somatostatin, which inhibits the secretion of insulin and glucagon. There are five types of cells in the pancreatic islets: $\beta$-cells secreting insulin; alpha cells secreting glucagon, delta cells secreting somatostatin, epsilon cells secreting ghrelin (a so-called "hunger hormone" that stimulates food intake, fat deposition and growth hormone release), and pancreatic polypeptide (PP) secreting cells, which regulate endocrine and exocrine secretory functions of the pancreas. In addition, the pancreatic islets contain a population of resident islet macrophages. The islet macrophages are self-renewed and are rarely, if not at all, replenished by the bone marrow/bloodderived monocytes (Carrero et al. 2017). Islet macrophages are situated in the vicinity of the blood vessels, and they communicate with the cellular and acellular components of the blood through the filopodia that extend to the lumen of the vessels. They also interact with the $\beta$-cells, capturing insulin and presenting it to the autoreactive $\mathrm{CD}^{+} 4 \mathrm{~T}$ cells, which are critical for the immune response. Islet macrophages express both stimulatory and suppressive ligands and receptors, chemokines, and cytokines including IL- $1 \beta, \mathrm{TNF} \alpha$, and a high level of major histocompatibility complex MHC-II, and as such are the key regulator of the activation and recruitment of the lymphocytes, and additional monocyte/macrophages into the islets during the infection (Calderon et al. 2011, 2015; Carrero et al. 2017; Ferris et al. 2017; Vomund et al. 2015). For example, Carrero et al. (2017) showed that in the autoimmune 
diabetes nude mouse model, the deepletion of the islet macrophages using monoclonal antibody against the macrophage colony-stimulating factor1 (CSF-1) receptor decreses a recruitment of $\mathrm{T}$ cells into the islets.

\section{Pancreatic macrophages in Diabetes mellitus (DM)}

Diabetes mellitus (DM) results from the loss of functional $\beta$ cell mass in the pancreas. There are two main forms of DM: type 1 diabetes mellitus (T1DM) or Insulin-Dependent Diabetes Mellitus (IDDM; which accounts for $5-10 \%$ of all diabetic patients) and type 2 diabetes mellitus (T2DM) also known as Noninsulin-Dependent Diabetes Mellitus (NIDDM; which accounts for $90-95 \%$ of all diabetic patients). Preclinical and clinical studies indicate that the increased numbers of innate immune cells, and produced by them inflammatory factors have causative and detrimental effects on the islets and $\beta$-cells in diabetes (Böni-Schnetzler and Meier 2019). Molecular mechanisms leading to $\beta$-cell failures and cell death by apoptosis in T1DM and T2DM are distinct. While T1DM is immune-mediated, T2DM is metabolic-, mostly lipid-, mediated, and associated with obesity. These two mechanisms differently affect not only $\beta$-cells, but also the accompanying immune cells including macrophages, which are involved in the inflammatory processes associated with DM (Eizirik et al. 2020; Ying et al. 2020). The $\beta$-cell apoptosis is driven by the increase in mitogen-activated protein kinases triggering ER stress and followed by the release of apoptotic signals from the mitochondria both in T1DM and T2DM. However, two different gene cascades seem to be involved in each case: inositol-requiring enzyme 1 (IRE1)driven genes in T1DM and the protein kinase RNA-like endoplasmic reticulum kinase PERK/ Eukaryotic Initiation Factor 2 alpha (eIF2 $\alpha$ )-dependent pathway in T2DM (Cnop et al. 2005; Eizirik et al. 2020). Both T1DM and T2DM also affect the function of resident and recruited monocytes/ macrophages that are essential for the innate immune response, cytokine secretion, phagocytosis, tissue homeostasis, and remodeling (Murray and Wynn 2011). DM, mostly via high glucose levels, modifies monocyte/macrophage metabolism causing failures in the innate immune and inflammatory processes (Ayala et al. 2019; Casqueiro et al. 2012; Esper et al. 2008). This is due in part to the changes in macrophage epigenetic profile, which modify their predisposed inflammatory state (van Diepen et al. 2006). Some of the DM-induced changes in macrophage functions are common to T1DM and T2DM, and some are distinct. For instance, in both DM variants, the proinflammatory cytokine or macrophage migration inhibitory factor Mif, is highly expressed and its level is elevated in the serum. The studies in the mouse model showed that Mif plays a crucial role in macrophages and dendritic cells activation (another type of innate immune system cells), lowers the levels of inflammatory cytokines, hyperglycemia, specific pancreatic islet antigen- (PIAg-) IgG, and reduces macrophages infiltration into the pancreatic islets (SánchezZamora et al. 2016).

T1DM causes specific signal transduction dysregulations in the macrophages. The comparison of bone marrow-derived macrophages (BMDM) and peritoneal macrophages in nondiabetic and diabetic $\mathrm{C} 57 \mathrm{BL} / 6$ male mice, the animal model for T1DM, has shown, recently, the dysregulation of both Pl3K/AKT, ERK 1/2 and SAPK/JNK protein kinases pathways and the secretion of cytokines, such as tumor necrosis factor (TNF)- $\alpha$, interleukin (IL)-6 and IL-10 (Galvão Tessaro et al. 2020). Thus, in the T1DM, the macrophage-dependent innate immune response is significantly altered. In T2DM, both macrophages and NK cells show important modifications in the abilities to chemotaxis, and phagocytosis (Lecube et al. 2011), the functions playing a pivotal role in the initial stages of the fight against infection. Decrease of these functions condemns T1DM and T2DM patients to delayed and weaker immune defense already in the initial stages of infection, including SARS-CoV-2, which is today of the particular interest.

However, macrophages can not only protect but also aggravate the DM by augmenting pancreatic islets inflammation, and affecting $\beta$ cell proliferation (Ying et al. 2019). Studies in diabetes 1 mouse model showed that diabetes promotes an inflammatory monocyte/macrophage phenotype (Kanter et al. 2012).

These data indicate that although the macrophages can have both protective and destructive roles depending on the pathologic context (Ying et al. 2020), their function in DM is skewed toward the inflammatory (and eventually damaging) response.

\section{Increased ACE2 expression in DM and the SARS-CoV-2 infection}

Although the general understanding is that the frequency of microbial infections in diabetic patients is the same as in the general population, some studies are indicating that diabetic patients have a higher risk of infections (Casqueiro et al. 2012; Carey et al. 2018; Critchley et al. 2018). Most importantly everybody agrees that infected diabetic patients have higher morbidity and mortality. This is also true for coronaviruses infections, such as SARS, MERS, and the current SARSCoV-2responsible for the current COVID-19 pandemic. The one of the resaons of high morbidity of COVID-19 is directly related to the overstimulation of lung macrophages and overproduction of inflammatory cytokines, a so called cytokine storm that results in the caute respiratory distress syndrome (ARDS) (Kloc et al. 2020). Higher probability for diabetic 
patients to develop higher SARS-CoV-2 viral load and more severe symptoms are related to the increased expression of Angiotensin-converting-enzyme 2 or ACE2 - the receptor for coronaviruses entry to human cells (Roca-Ho et al. 2017; Yang et al. 2020; Fang 2020; Richardson et al. 2020; Erener 2020). ACE2 is expressed in the lung, heart, adipose tissue, kidney, pancreas (especially in $\beta$-cells), the luminal surface of the small intestine, and blood vessels (Hamming et al. 2004; Monteil et al. 2020; Ziegler et al. 2020). The ACE2 is also expressed in the macrophages and monocytes (Chen et al. 2020; Rutkowska-Zapała et al. 2015), and its expression is stimulated by the inflammatory signals, such as type I interferon, produced by macrophages (Ziegler et al. 2020) Moreover, the medications with which diabetic patients are treated, e.g. glucagon-like peptide I (GLP-1) agonists, or hypertension medications, and statins, increase the ACE2 expression even more (Drucker 2020). Thus, diabetic patients become not only the privileged target for SARS-CoV-2 infection, but they may also develop a higher viral load because of the overexpression of ACE2 viral receptors in many cell types, nurturing SARS-CoV-2 replication.

\section{How can COVID-19 elicit DM?}

The possibility that COVID-19 may elicit DM in susceptible patients has been evoked recently (Rubino et al. 2020; Caruso et al. 2020). It seems to be confirmed by recent case reports (Marchand et al. 2020). Such a hypothesis has been already proposed following the SARS epidemic in 2002 (Yang et al. 2010). As we wrote above, SARS-CoV-2 infects many types of cells expressing ACE2 receptors, including the macrophages and $\beta$-cell in the pancreas. We postulate that there are several plausible mechanisms responsible for the triggering of DM in COVID-19. One possibility is that, similar to the effect of SARS-CoV-2 in the lungs, the infection of pancreatic macrophages causes inflammatory cytokine and chemokines storm in the pancreas. This, in turn, recruits additional immune cells, including proinflammatory monocyte/macrophage, causing additional damage to the pancreatic islets and $\beta$-cells. The second possibility is that because macrophages and monocytes are motile, after being infected with SARS$\mathrm{CoV}-2$, they disseminate virus to the and within the pancreas (Klepper and Branch 2015). Another possibility is that the SARS-CoV-2 infection of the $\beta$-cells, directly damages them, causing apoptosis, and reducing $\beta$-cell mass in the pancreas. Although, this scenario seemed the least likely because the direct damage to the pancreatic islets should result in higher than the reported incidence of COVID-19-induced diabetes, however, recent data presented in Nature News indicate that indead, the SARS-CoV-2 may cause direct damage to the insulin producing $\beta$-cells (Mallapaty 2020). Although, most probably, the combination of these different mechanisms is responsible for the development of DM in COVID-19 patients further preclinical and clinical studies, and analyses are necessary to give definite answers.

Acknowledgements While writing this article JZK was supported by the grant "Kościuszko" \# 5508/2017/DA from the Polish Ministry of National Defense.

\section{Compliance with ethical standards}

Conflict of interest The authors declare that they have no conflict of interest.

\section{References}

Ayala TS, Tessaro FHG, Jannuzzi GP, Bella LM, Ferreira KS, Martins JO. High glucose environments interfere with bone marrow-derived macrophage inflammatory mediator release, the TLR4 pathway and glucose metabolism. Sci Rep. 2019;9(1):11447.

Böni-Schnetzler M, Meier DT. Islet inflammation in type 2 diabetes. Semin Immunopathol. 2019;41:501-13. https://doi.org/10.1007/ s00281-019-00745-4.

Calderon B, et al. The pancreas anatomy conditions the origin and properties of resident macrophages. J Exp Med. 2015;212:1497-512.

Calderon B, Carrero JA, Miller MJ, Unanue ER. Cellular and molecular events in the localization of diabetogenic $\mathrm{T}$ cells to islets of Langerhans. Proc Natl Acad Sci USA. 2011;108:1561-6.

Carey IM, Critchley JA, DeWilde S, Harris T, Hosking FJ, Cook DG. Risk of infection in type 1 and type 2 diabetes compared with the general population: a matched cohort study. Diabetes Care. 2018;41(3):513-21.

Carrero JA, McCarthya DP, Ferrisa ST, et al. Resident macrophages of pancreatic islets have a seminal role in the initiation of autoimmune diabetes of NOD mice. Proc Natl Acad Sci U S A. 2017;114(48): E10418-27. https://doi.org/10.1073/pnas.1713543114.

Caruso P, Longo M, Esposito K, Maiorino MI. Type 1 diabetes triggered by covid-19 pandemic: A potential outbreak? Diabetes Res Clin Pract. 2020;164:108219. https://doi.org/10.1016/j.diabres.2020. 108219.

Casqueiro J, Casqueiro J, Alves C. Infections in patients with diabetes mellitus: a review pathogenesis. Indian J Endocrinol Metab. 2012;16:27-36.

Chen Y, et al. The novel severe acute respiratory syndrome coronavirus 2 (SARS-CoV-2) directly decimates human spleens and lymph nodes. Preprint at. medRxiv. 2020. https://doi.org/10.1101/2020.03.27. 20045427.

Cnop M, Welsh N, Jonas J-Ch, Jörns A, Lenzen S, Eizirik DL. Mechanisms of pancreatic $\beta$-cell death in type 1 and type 2 diabetes: many differences, few similarities. Diabetes. 2005;54(Suppl. 2):97107.

Critchley JA, Carey IM, Harris T, DeWilde S, Hosking FJ, Cook DG. Glycemic control and risk of infections among people with type 1 or type 2 diabetes in a large primary care cohort study. Diabetes Care. 2018;41(10):2127-35.

Drucker DJ, Coronavirus Infections and type 2 diabetes-shared pathways with therapeutic implications. Endocr Rev. 2020;41(3):bnaa011.

Eizirik DL, Pasquali L, Cnop M. Pancreatic $\beta$-cells in type 1 and type 2 diabetes mellitus: different pathways to failure. Nat Rev Endocrinol. 2020;16(7):349-62. https://doi.org/10.1038/s41574-020-0355-7.

Erener S. Diabetes, infection risk and covid-19. Mol Metab. 2020;101044. https://doi.org/10.1016/j.molmet.2020.101044. 
Esper MA, Moss M, Martin GS. The effect of diabetes mellitus on organ dysfunction with sepsis: an epidemiological study. Crit Care. 2008;13:R18.

Fang L, Karakiulakis G, Roth M. Are patients with hypertension and diabetes mellitus at increased risk for COVID-19 infection? Lancet. 2020;8(4):e21. https://doi.org/10.1016/S2213-2600(20) 30116-8.

Ferris ST, et al. The islet-resident macrophage is in an inflammatory state and senses microbial products in blood. J Exp Med. 2017;214: 2369-85.

Galvão Tessaro FH, Ayala TS, Bella LM, Martins JO. Macrophages from a type 1 diabetes mouse model present dysregulated Pl3K/AKT, ERK $1 / 2$ and SAPK/JNK levels. Immunobiology. 2020;225(2): 151879 .

Hamming I, Timens W, Bulthuis ML, Lely AT, Navis G, van Goor H. Tissue distribution of ACE2 protein, the functional receptor for SARS coronavirus: a first step in understanding SARS pathogenesis. J Pathol. 2004;203:631-7.

Kanter JE, Kramer F, Barnhart S, Averill MM, Vivekanandan-Giri A, Vickery T, Li LO, Becker L, Yuan W, Chait A, Braun KR, PotterPerigo S, Sanda S, Wight TN, Pennathur S, Serhan CN, Heinecke JW, Coleman RA, Bornfeldt KE. Diabetes promotes an inflammatory macrophage phenotype and atherosclerosis through acyl-CoA synthetase. Proc Natl Acad Sci U S A. 2012;109(12):E715-24. https://doi.org/10.1073/pnas.1111600109.

Klepper A, Branch AD. Macrophages and the Viral Dissemination Super Highway. EC Microbiol. 2015;2(3):328-36.

Kloc M, Ghobrial RM, Kubiak JZ. How nicotine can inhibit cytokine storm in the lungs and prevent or lessen the severity of COVID-19 infection? Immunol Lett. 2020;224(2020):28-9. https://doi.org/10. 1016/j.imlet.2020.06.002.

Lecube A, Pachon G, Petriz J, Hernandez C, Simo R. Phagocytic activity is impaired in type 2 diabetes mellitus and increases after metabolic improvement. PLoS One. 2011;6(8):e23366.

Mallapaty S. Mounting clues suggest the coronavirus might trigger diabetes. Nature. 2020;583(7814):16-7.

Marchand L, Pecquet M, Luyton C. (2020). Type 1 diabetes onset triggered by COVID-19. Advance online publication. https://doi.org/ 10.21203/rs.3.rs-38116/v1.

Monteil V, Kwon H, Prado P, Hagelkruys A, Wimmer RA, Stahl M, et al. Inhibition of SARS-CoV-2 infections in engineered human tissues using clinical-817 grade soluble human ACE2. Cell. 2020;181(4): 905-13.e7. https://doi.org/10.1016/j.cell.2020.04.004.

Murray PJ, Wynn TA. Protective and pathogenic functions of macrophage subsets. Nat Rev Immunol. 2011;11(11):723-37. https://doi. org/10.1038/nri3073.

Richardson S, Hirsch JS, Narasimhan M, Crawford JM, McGinn T, Davidson KW, et al. Presenting characteristics, comorbidities, and outcomes among 5700 patients hospitalized with COVID-19 in the New York City area. JAMA. 2020;323(20):2052-9.

Roca-Ho H, Riera M, Palau V, Pascual J, Soler MJ. Characterization of ACE and ACE2 expression within different organs of the NOD mouse. Int J Mol Sci. 2017;18(3):563.

Rubino F, Amiel SA, Zimmet P, Alberti G, Bornstein S, Eckel RH, Mingrone G, Boehm B, Cooper ME, Chai Z, Del Prato S, Ji L, Hopkins D, Herman WH, Khunti K, Mbanya JC, Renard E. Newonset diabetes in covid-19. N Engl J Med, NEJMc2018688. Advance online publication. 2020.https://doi.org/10.1056/ NEJMc2018688).

Rutkowska-Zapała M, Suski MR, Szatanek R, Lenart M, Weglarczyk K, Olszanecki R, Grodzicki T, Strach, Gasowski M, Siedlar M. Human monocyte subsets exhibit divergent angiotensin I-converting activity. Clin Exp Immunol. 2015;181:126-32.

Sánchez-Zamora YI, Juarez-Avelar I, Vazquez-Mendoza A, Hiriart M, Rodriguez-Sosa M. Altered macrophage and dendritic cell response in Mif-/- mice reveals a role of Mif for inflammatory-Th1 response in type 1 diabetes. J Diabetes Res. 2016;2016:7053963. https://doi. org/10.1155/2016/7053963.

van Diepen JA, Thiem K, Stienstra R, Riksen NP, Tack CJ, Netea MG. Diabetes propels the risk for cardiovascular disease: sweet monocytes becoming aggressive? Cell. Mol Life Sci. 2006;73:4675-84.

Vomund AN, et al. Beta cells transfer vesicles containing insulin to phagocytes for presentation to T cells. Proc Natl Acad Sci USA. 2015;112:E5496-502.

Yang J-K, Lin S-S, Ji X-J, Guo L-M. Binding of SARS coronavirus to its receptor damages islets and causes acute diabetes. Acta Diabetol. 2010;47:193-9.

Yang X, Yu Y, Xu J, Shu H, Xia J, Liu H, et al. Clinical course and 748 outcomes of critically ill patients with SARS-CoV-2 pneumonia in Wuhan, China: a single-centered, retrospective, observational study. Lancet Respir Med. 2020;8(5):475-81.

Ying W, et al. Expansion of islet- resident macrophages leads to inflammation affecting beta cell proliferation and function in obesity. Cell Metab. 2019;29:457-74 e455.

Ying W, Fu W, Lee YS, Olefsky JM. The role of macrophages in obesityassociated islet inflammation and $\beta$-cell abnormalities. Nat Rev Endocrinol. 2020;16(2):81-90. https://doi.org/10.1038/s41574019-0286-3.

Ziegler CGK, et al. SARS-CoV-2 receptor ACE2 is an interferonstimulated gene in human airway epithelial cells and is detected in specific cell subsets across tissues. Cell. 2020;181(5):1016-35.e19. https://doi.org/10.1016/j.cell.2020.04.035.

Publisher's note Springer Nature remains neutral with regard to jurisdictional claims in published maps and institutional affiliations. 